\title{
Film Animasi Malaysia: Narasi Verbal ke Visual
}

\author{
Ahmad Nizam bin Othman \\ Program Doktor Ilmu Seni Rupa dan Desain, \\ Institut Teknologi Bandung, Indonesia
}

\begin{abstract}
Among the issues are to look into the approaches and education problems that happen in the verbal narration in old society and how the construction and preservation of legends and folklore into animation forms. This paper is to identify the icon, structure and method that use in film animation to emphasize the culture understanding of the legends and folklore. The ideas of this paper are to identify form; icon and meaning that attach in local folklore and translated into animation based on culture theory. This case study research involves collecting data through documentation; including interview method, observation and visual understanding on animation collection. The data analysis concentrates on technique and overall animation process, focusing on its impact on culture and local society. Legend and folklore are a part of Malays tradition culture that has been spreading and handing on from one generation to another. The story of fairy tales, myths, extraordinary and miraculous of early centuries of human evolution now been represent in new form, that involved visual and other human sense's. This paper will discuss about the condition of the understanding and imaginations in this new generation are still same as early century about the beauty of Mahsuri, the extraordinary and enthusiastic of Hang Tuah and the kindheartedness of Bawang Putih. How human accepted and preserves tradition and culture customs but in adaptation process, upgrading and decent with civilization maturity. The outcome are expected to contribute in preserving culture and tradition..
\end{abstract}

Keywords: animation; legend; narration; storytelling.

\section{Pendahuluan}

Karya seni dapat diartikan sebagai ide dan gagasan manusia yang diekspresikan melalui medium dan teknik tertentu sehingga menghasilkan karya seni yang indah dan bermakna.Karya seni adalah hasil dari tingkah laku manusia. Sesebuah karya seni itu dipandang dari sudut keindahan pada karyanya dan dari sudut lingkungan, nilai-nilai, pengetahuan dan unsur-unsur lingkungannya.

Perkembangan teknologi dan komunikasi membawa pengaruh yang luar biasa pada kehidupan dan cara pandang manusia terhadap teknologi. Pada zaman kemodenan ini, papan iklan dicetak dan dipaparkan kepada umum dengan mesej untuk dibaca dan difahami oleh sesiapa saja yang melihatnya. Sedangkan masyarakat terdahulu menganggap bahwa Seni Batu (lukisan dinding) adalah 
lebih simbolik, spiritual, ekspresi beserta kepercayaan tahyul yang masih utuh dalam pemikiran dan pegangan hidup mereka. Pengaruh teknologi pada kesenian memberikan pergeseran konsep berkarya. Sebagai contoh, teknologi photografi pertama adalah digunakan untuk membantu seniman melukis gambar kepada lebih realistik. [1]

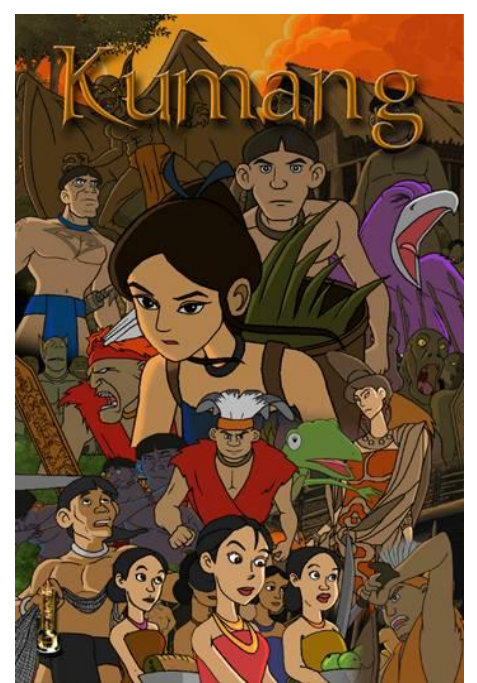

(a)

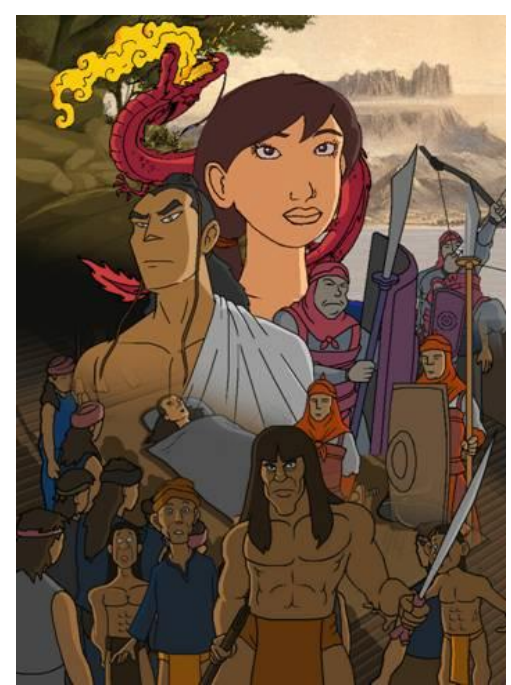

(b)

Gambar 1 (a) Animasi Kumang; (b) Legend of Kinabalu (sumber: http://www.quest-animation.com).

Manusia sebolehnya coba mengekalkan warisan kebudayaan $^{1}$ dengan mendedahkan dan menanamkan hikayat dan legenda kepada generasi baru, antaranya melalui illustrasi, buku cerita, film dan animasi. Antara animasi yang diadaptasi dari kesusasteraan Melayu klasik ${ }^{2}$ adalah film animasi 'Silat Legenda', 'Putih'; rangkaian animasi pendek 'Hikayat Sang Kancil' dan 'Saladdin' manakala untuk rangkaian animasi televisi antaranya 'Kampung Boy' dan 'Badang'. Quest Animations (M) Sdn Bhd, antara yang aktif dalam

1 Geertz mengatakan bahwa kebudayaan merupakan suatu pola makna yang ditularkan secara historis, yang diejawantahkan dalam simbol-simbol, suatu sistem konsep yang diwarisi, terungkap dalam bentuk-bentuk simbolis, yang menjadi sarana manusia untuk menyampaikan, mengabdikan dan mengembangkan pengetahuan mereka tentang serta sikap-sikap mereka terhadap kehidupan. [2]

2 Kesusasteraan Melayu klasik adalah sastra yang hidup dan berkembang sebelum dan sesudah Islam hingga tahun 1920-an. Dalam sastra lisan, bahasa adalah sebagai media utama dalam menyampaikan puisi dan prosa. Ianya juga disebut sebagai sastra rakyat yang mana muncul dan berkembang di tengah-tengah kehidupan rakyat biasa. 
memproduksi animasi yang di adaptasi dari legenda seperti 'Kumang Legend of Sarawak', 'Legend of Kinabalu'.

Film animasi dikategorikan sebagai media hiburan dan pendidikan. Audien disasarkan kepada bukan saja untuk golongan kanak-kanak semata tetapi juga kepada semua lapisan masyarakat. Persoalannya tidak hanya berasaskan kepada fantasi dongengan, tetapi terkandung kritis sosial dan politik. Kini di Malaysia, film animasi sudah semakin maju dari pembuatan animasi tradisi kepada animasi tiga dimensi seiring kemajuan media, teknologi dan globalisasi.

\section{$2 \quad$ Animasi di Malaysia}

Animasi kini menjadi tumpuan dan perhatian di Malaysia khususnya dari pelbagai pihak termasuk pihak pemerintah karena kemampuannya untuk menjana ekonomi negara. Bermulanya kewujudan Koridor Raya Multimedia (MSC) di Cyberjaya dan E-Village, adalah sebagai pemangkin kepada sektor perfilman termasuk pembuatan film animasi local, dan ini merupakan antara langkah awal kepada pembangunan industri multimedia. Beberapa rencana dan dana kemudiannya diwujudkan sebagai sokongan, seperti Skim Pinjaman Film Cereka (SPFC) dan Geran Pembinaan Film Animasi dari Kementerian Sains dan Teknologi Malaysia (MOSTI).

Seiring dengan gagasan Malaysia untuk memacu dan memperkasa perkembangan ekonomi yang berasaskan pengetahuan (k-economy), pengwujudan jurusan dan mata kuliah dalam bidang animasi, multimedia dan kreatif di universitas, institut dan perguruan tinggi tumbuh bagaikan cendawan. Terdapat juga perguruan tinggi dan pusat akademik yang diwujudkan sematamata berfokus kepada bidang animasi dan multimedia. Ini secara langsung akan melahirkan animator, pereka dan tenaga mahir dari segi rekabentuk, kreativitas dan teknis yang mampu menghasilkan karya dan produk yang bisa bersaing di pasaran gobal, dengan harapan melakar sebuah senario dunia animasi Malaysia.

Bermulanya animasi di Malaysia adalah dengan pembentukan Unit Filem Malaya (yang kini dikenali sebagai Filem Negara Malaysia). Keterlibatan dalam bidang animasi ketika itu hanya sekadar untuk menerbitkan film dokumentasi dan pengiklanan. Bidang animasi di Malaysia kemudiannya mengalami perubahan dengan pengaruh daripada teknologi digital dan memberikan pengaruh yang kuat kepada industri animasi lokal dengan kemunculan film animasi pertama Malaysia yaitu 'Silat Legenda' dan dimainkan di gedung bioskop pada tahun 1998. Kini pembangunan industri animasi di Malaysia semakin memberangsangkan dan juga turut membabitkan produk dalam bentuk kartun, iklan dan penyiaran gambar berunsurkan hiburan dan pendidikan. 
Animasi lokal Malaysia dimulai dengan Hikayat Sang Kancil yang disiarkan di televisi pada 1983. Atas kejayaan film animasi pendek ini, produksi animasinya dikembangkan antara tahun 1984 hingga 1987, menghasilkan beberapa rangkaian animasi yaitu antaranya 'Sang Kancil dan Monyet', 'Sang Kancil dan Buaya', 'Gagak Yang Bijak', 'Arnab Yang Sombong' dan 'Singa Yang Haloba'. Berkembangnya teknologi digital sekitar tahun 1980-an, telah memunculkan animasi televisi yang pertama yaitu 'Usop Sontorian' pada 1998. Malaysia kemudiannya melibatkan diri secara serius dalam industri animasi dengan menerbitkan animasi untuk layar lebar yang dimulai oleh film 'Silat Legenda' (1998) dan diikuti oleh 'Cheritera' (2001), 'Putih' (2001), 'Budak Lapok' (2007) dan yang terbaru yaitu 'Geng: Pengembaraan Bermula' (2009). Terdapat juga animasi yang menggunakan karakter-karakter kartun sebagai karakter utama dalam animasi seperti Kampung Boy dan Mat Gelap (yang menggabungkan live action dan animasi). [3]

\section{$3 \quad$ Dongeng dan Hikayat}

Kesusasteraan Melayu di waktu silam dikenali sebagai 'hikayat' dan warisan dari penceritaan lisan. Hikayat berasal dari bahasa Arab 'hikayah' yang berarti kisah, cerita atau dongeng. Legenda (legere-dalam Latin) pula adalah cerita prosa rakyat dan sering kali dianggap sebagai "sejarah" kolektif (folk history). Hikayat dan dongeng adalah sebahagian kebudayaan suatu kolektif, yang tersebar dan diwariskan turun temurun, di antara kolektif macam apa saja, secara tradisional dalam versi yang berbeda.

Cerita rakyat terdiri dari kisah, cerita, hikayat dan dongeng, merupakan bahasa tutur yang terkandung agama dan kepercayaan, undang-undang dan kegiatan ekonomi. Ia tersebar dan diwariskan secara turun temurun dari generasi ke generasi, di antara kolektif macam apa saja, secara tradisi dalam versi yang berbeda, dan berfungsi sebagai media pendidikan, pengajaran moral, hiburan dan proses sosial. Kemunculan hikayat dan dongeng ini merupakan kelanjutan dari cerita penglipur lara yang berkembang dalam tradisi lisan di masyarakat, kemudian diperkaya dan diperindah. Ia bertujuan sebagai bahan pengajaran kepada kanak-kanak dengan perspektif yang positif dan mendidik mereka dengan sopan-santun dan adat tradisi. Hikayat tempatan yang banyak mempengaruhi masyarakat Melayu amnya, berfungsi sebagai media didaktik (pendidikan) dan hiburan dalam masyarakat.

Hikayat lokal yang banyak mempengaruhi masyarakat Melayu, berfungsi sebagai media didaktik (pendidikan) dan hiburan dalam masyarakat. Narasi ${ }^{3}$

3 Suatu narasi atau story structure mempunyai tiga dasar utama yaitu permulaan (exposition), pertengahan (conflict), dan penamat (resolution). Setiap cerita dan 
dalam hikayat dan dongeng, sebagai media didaktik dan hiburan, mengandung bahan pengajaran tentang perspektif yang positif, sopan satun dan adat resam.

Penulisan ini memfokuskan kepada salah satu film animasi Malaysia yaitu film animasi Putih. Film ini yang diproduksi pada tahun 2001 adalah adaptasi cerita dongeng rakyat purbakala masyarakat lokal, 'Bawang Putih Bawang Merah' yang diturunkan secara verbal dari satu generasi ke generasi berikutnya dalam masyarakat Melayu. Cerita dongeng rakyat purbakala ini telah melalui pelbagai terjemahan, bermula dari penyampaian secara lisan dalam masyarakat Melayu dahulu kala, kemudian dituliskan dalam hikayat dan sastra tulisan. Cerita dongeng rakyat ini pernah difilmkan melalui film Bawang Merah Bawang Putih pada tahun 1959 dan terus diadaptasi dan dikembangkan sehingga ke hari ini baik dalam bentuk cetak maupun dunia digital.

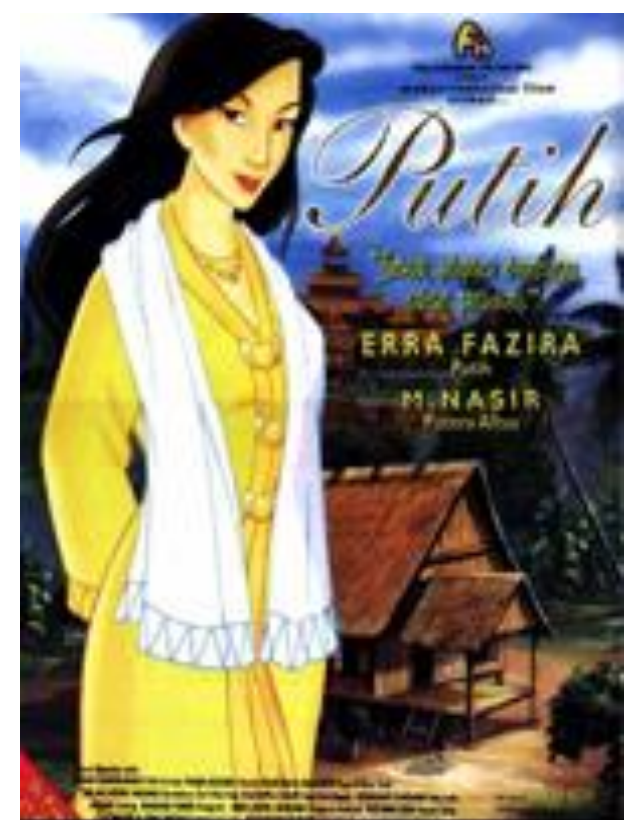

Gambar 2 Poster Film Animasi Putih 2001.

storytelling akan mempunyai permulaan cerita (exposition). Ini perlu untuk memperkenal karakter, 'setting' cerita dan sebagainya. Pada bagian pertengahan (conflict), adalah tempat berkembangnya aksi atau konflik dalam sesebuah cerita. Seiring dengan perkembangan cerita, konflik akan bertambah dan menuju kemuncak yaitu klimaks cerita. Selepas berakhir tahap klimaks, berkemungkinan akan ada perincian atau secondary event dan setiap karakter memerlukan masa untuk melengkapkan sepenuhnya cerita. Disinilah bagian penamat (solution) berperanan untuk merangkumi elemen-elemen cerita tadi. [4] 
Secara ringkasnya, cerita dongeng rakyat purba ini mengisahkan berkenaan seorang gadis bernama bawang putih yang cantik, pintar dan baik hati yang saban hari didera ibu dan kakak tirinya selepas kematian bapaknya. Akhirnya dia berjaya keluar dari kongkongan ibu dan kakak tirinya, dan mengahwini putera raja. Kebijaksanaan dan hati yang nurani, memunculkannya sebagai tokoh wanita, anak dan isteri yang menjadi idola kepada masyarakat.

\section{Transformasi Dongeng ke Animasi}

Makna kunci untuk istilah 'transformasi' adalah perubahan atau peralihan ${ }^{4}$. S.K. Langer mengatakan transformasi merujuk kepada penterjemahan rupa yang menjadi hasrat kepada karya seni tanpa representasi yang sebenarnya, dengan produksi terhadap equivalent sense-impression daripada serupa secara harfiah, atau istilah lainnya iaitu material yang limited dan legitimate yang tidak boleh secara naïf meniru hasrat yang dimiliki oleh 'model'. [5]

Terjadinya transformasi adalah mensyaratkan adanya pemunculan simbol dan tanda ke dalam kondisi dan atau lingkungan yang lain. Dengan pemunculan yang berbeda itulah simbol dan tanda mengalami perubahan-perubahan. Jika dikaitkan dengan narasi verbal dan visual naratif seperti dalam rumusan permasalahan di atas, istilah transformasi diartikan sebagai pemunculan, pengambilan atau pemindahan unsur-unsur simbolik dalam narasi verbal ke dalam unsur visual naratif dengan perubahan.

\section{$5 \quad$ Analisis}

Analisis Intraestetik di sini merupakan faktor-faktor yang mengacu pada karya itu sendiri yaitu ide gagasan, media teknik dan karya. Analisis Intraestetik memberi penumpuan kepada teknik dan kaedah pembikinan animasi secara keseluruhan. Bermula dari bentuk ide dan gagasan yaitu melihat kognitif, konteks, nilai-nilai dan makna dalam narasi; kepada indikator terhadap media dan teknik karya yaitu proses menghasilkan bentuk-bentuk visual melalui figura (figures), pakaian dan alatan ekstra (clothing and accessories), dan gesture dan ekspresi wajah (gestures and facial expression); dan seterusnya visual keseluruhan, hasil karya seni itu (film animasi).

Indikator-indikator yang digunakan, adalah bertujuan sebagai penunjuk untuk melihat perubahan yang berlaku ke atas pemahaman dan penceritaan legenda

4 Mirzoeff mengatakan bahwa ciri yang paling menonjol dalam ' $n$ ew visual culture' adalah peningkatan kecenderungan untuk menvisualisasi benda yang bukan secara harfiah dirinya berbentuk visual. [6] 
Melayu. Ide dan gagasan dalam seni adalah bertitik tolak dari segala sesuatu yang ada di dalam dan di luar diri seniman melalui berbagai media, sebagai bahan pernyataan bentuk seni dan berhubungan erat dengan tujuan dari penciptaan seni. Medium di sini, mempunyai arti sarana yang menentukan batasan-batasan dari lingkup seni, yang digunakan dalam mewujudkan gagasan menjadi suatu karya seni melalui pemanfaatan material atau bahan dan alat serta penguasaan teknik berkarya. Ide dan perantaraan kepada ekspresi yaitu media dan teknik adalah dua aspek ekspresi yang tidak dapat dipisahkan. [7]

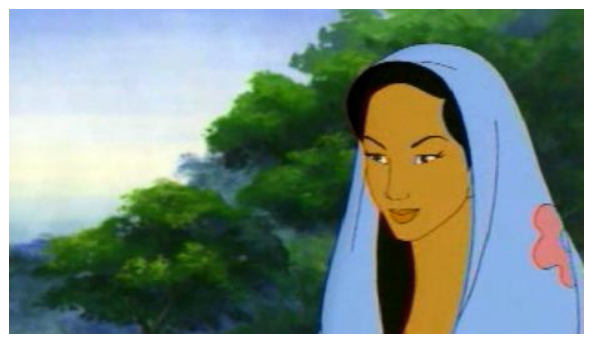

(a)

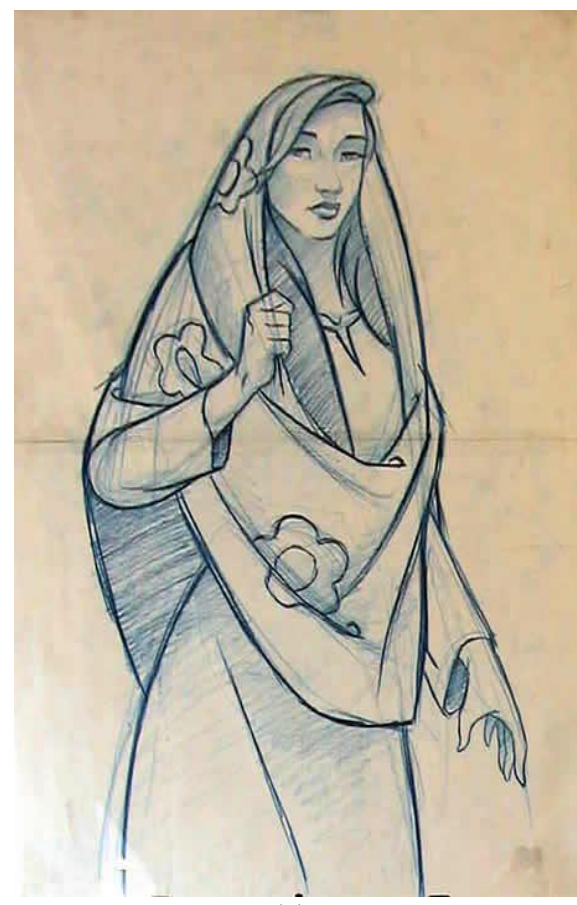

(c)

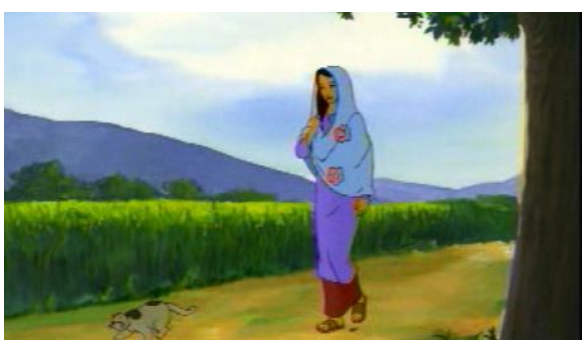

(b)

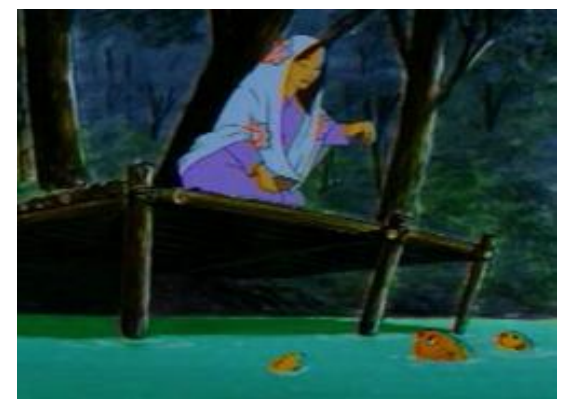

(d)

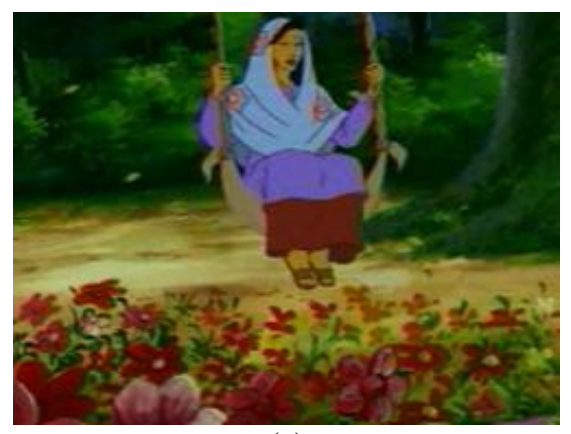

(e)

Gambar 3 (a)-(e): Posture, Clothing \& Accessories dan Gesture \& Facial Expression pada karakter Bawang Putih. 


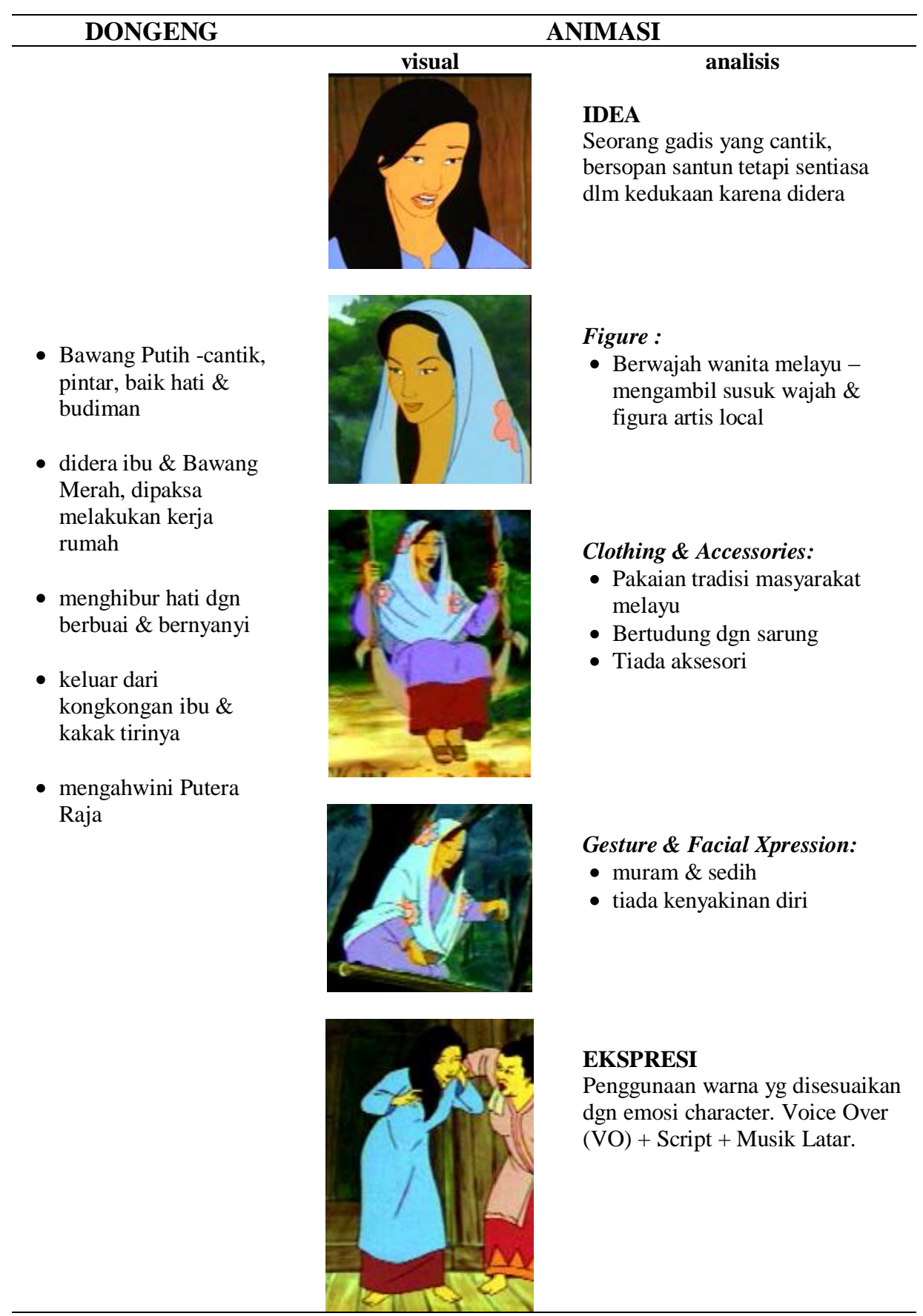

Gambar 4 Analisis Intaestetik. 
Daripada ide dan gagasan tadi, dituangkan ke dalam media dan teknik. Di sinilah beberapa perkara yang menjadi titik penting dalam merekabentuk sesebuah karakter, sesuai dengan jalan cerita dan ide. Figura (figures) untuk memperlihatkan kepada audien tentang kecantikan, bentuk badan dan sifat-sifat yang diwujudkan pada sesebuah karakter. Pakaian dan alatan ekstra (clothing and accessories) pula sebagai pelengkap kepada karakter sepanjang animasi. Ini untuk menyempurkan lagi ciri-ciri dan perwatakan karakter. Gesture dan ekspresi wajah (gestures and facial expression), antara yang terpenting dalam animasi. Setiap babak, adegan dan emosi yang dibawa di dalam cerita, akan dipaparkan secara langsung pada wajah karakter. Visualisasi yang dihasilkan merupakan gambaran secara keseluruhan animasi atau ekspresi dan karya seni itu sendiri.

Dalam narasi verbal, penumpuan kepada hubungan ide, media teknik, dan ekspresi karya seni dan kemudiannya diinterpretasikan untuk melihat makna dan perlambangan, sebagai simbolisme dalam menyampaikan nilai-nilai dan norma-norma masyarakat ketika itu yang diterjemahkan ke dalam bentuk visual secara imaginatif. Narasi visual juga akan dilihat melalui proses yang sama, penumpuan kepada ide, media teknik, dan ekspresi karya yaitu dalam bentuk animasi.

\section{Penutup}

Pihak produksi sedayanya menvisualisasikan kisah dongeng berpaksikan kepada masa dan keadaan lingkungan zaman Melayu klasik. Pada animasi ini, secara mata kasar dapat dilihat adanya kemasukan unsur-unsur dan elemenelemen baru dan lama bagi menghidupkan kisah dongeng pada masa kini.

\section{Daftar Pustaka}

[1] Branston, G. and Stafford, R. 1996. The media student's handbook, London: Routledge, p. 448.

[2] Dillistone, F. W. 2002. The Power of Symbols: Daya Kekuatan Simbol, Yogyakarta, Kanisius.

[3] Ngah, N.A. 2007. Perkongsian Duniaku dan Duniamu, Sejarah Awal Animasi Malaysia, http://jonos.blogspot.com/2007/05/sejarah-awalanimasi-malaysia.html,

[4] Block, B. A. 2001. The Visual Story, Seeing the Structure of Film, TV, and New Media, Oxford, U.K., Focal Press.

[5] Langer, S.K. 1957. Problems of Art, Ten Philosophical Lecturer, New York, Charles Scribner's Sons.

[6] Mirzoeff, N. 1999. An Introduction to Visual Culture, London \& New York, Routledge 
[7] Gaitskell, C.D., Gaitskell M.R. 1954. Art Education During Adolescence, New York, Harcourt, Brace and Company. 